\title{
Mixed Cerebral Palsy
}

National Cancer Institute

\section{Source}

National Cancer Institute. Mixed Cerebral Palsy. NCI Thesaurus. Code C97177.

A subtype of cerebral palsy characterized by both the tight muscle tone of spastic cerebral palsy and the writhing, involuntary muscle movements of athetoid cerebral palsy. 